Short Communication

\title{
Molecular systematics of the Cyprinoidea (Teleostei: Cypriniformes), the world's largest clade of freshwater fishes: Further evidence from six nuclear genes
}

\author{
Wei-Jen Chen *, Richard L. Mayden \\ Department of Biology, Saint Louis University, 3507 Laclede Ave., St. Louis, MO 63103, USA
}

\section{A R T I C L E I N F O}

\section{Article history:}

Received 12 December 2008

Available online 21 January 2009

\section{Keywords:}

Cyprinidae

Cyprinioidea

Cypriniformes

Psilorhynchus

Tinca

Leptobabrus

Nuclear gene

Phylogenomics

Taxonomic chaos

\section{Introduction}

With over 210 genera and 2010 described species, the family Cyprinidae is currently the largest family of freshwater fishes (Nelson, 2006). Over the years, the Cyprinidae has been divided into different "groupings" for either taxonomic convenience or to represent presumed natural groups; usually these groupings have been recognized at or below the level of subfamily (Cavender and Coburn, 1992; Howes, 1991; Nelson, 2006). Howes (1991) recognized seven such subgroupings of the Cyprinidae, including the Alburninae, Cyprininae, Rasborinae, Cultrinae, Acheilognathinae, Tincinae, Leuciscinae, and Gobioninae. Cavender and Coburn (1992) recognized two, the Cyprininae and Leuciscinae, the former including those cyprinids referred to as barbins, labeonins and cyprinins, and the later including those referred to as tincins, rasborins, gobionins, acheilognathins, cultrins, xenocyprins, leucisins and phoxinins. The genus Psilorhynchus (a grouping of small, ventrally flattened fishes adapted for benthic life in fast flowing water) is either considered to be the sole member of the family Psilorhynchidae (Conway and Mayden, 2007; Nelson, 2006; Ramaswami, 1952) following Hora (1925) or as the sole member of the cyprinid subfamily Psilorhynchinae (Chen, 1981; Nelson, 1994).

\footnotetext{
* Corresponding author. Fax: +1 314977365.

E-mail address: wjchen.actinops@gmail.com (W.-J. Chen).
}

Previous systematic analyses investigating monophyly and inter-relationships of the Cyprinidae have focused largely on morphology or mitochondrial gene/genome sequences. Chen et al. (1984) was the first such study to propose a "phylogenetic" hypotheses" of cyprinid inter-relationships based on morphological data. Later Cavender and Coburn (1992) reanalyzed the data matrix of Chen et al. (1984), recovering a tree of equal length but of a different topology to that recovered by Chen et al. (1984) (Fig. 1B). Cavender and Coburn (1992) also proposed an alternative phylogeny for the Cyprinidae based on the analysis of their own 47 morphological characters (Fig. 1A). Despite these early morphological phylogenetic investigations of the Cyprinidae, some uncertainty regarding the basal lineage of cyprinds and the placement of the enigmatic genus Tinca remains (Fig. 1).

Recent systematic investigations of the Cyprinidae have utilized a molecular phylogenetic approach, with mitochondrial sequence data being most readily utilized (e.g., Cunha et al., 2002; Gilles et al., 2001; He et al., 2008a; Liu and Chen, 2003; Okazaki et al., 2001; Saitoh et al., 2006; Simons et al., 2003; Xiao et al., 2001; Zardoya and Doadrio, 1998). Although the taxonomic sampling of these studies was limited to certain subgroupings or to species from geographic regions of interests to the authors each of these investigations provided valuable insight into the evolution of these morphologically diverse fishes. Two studies presented their hypotheses with the samplings covering approximately all cyprinid subfamilies (Gilles et al., 2001; Liu and Chen, 2003). Both of these studies resolved Tinca as more closely related to members 

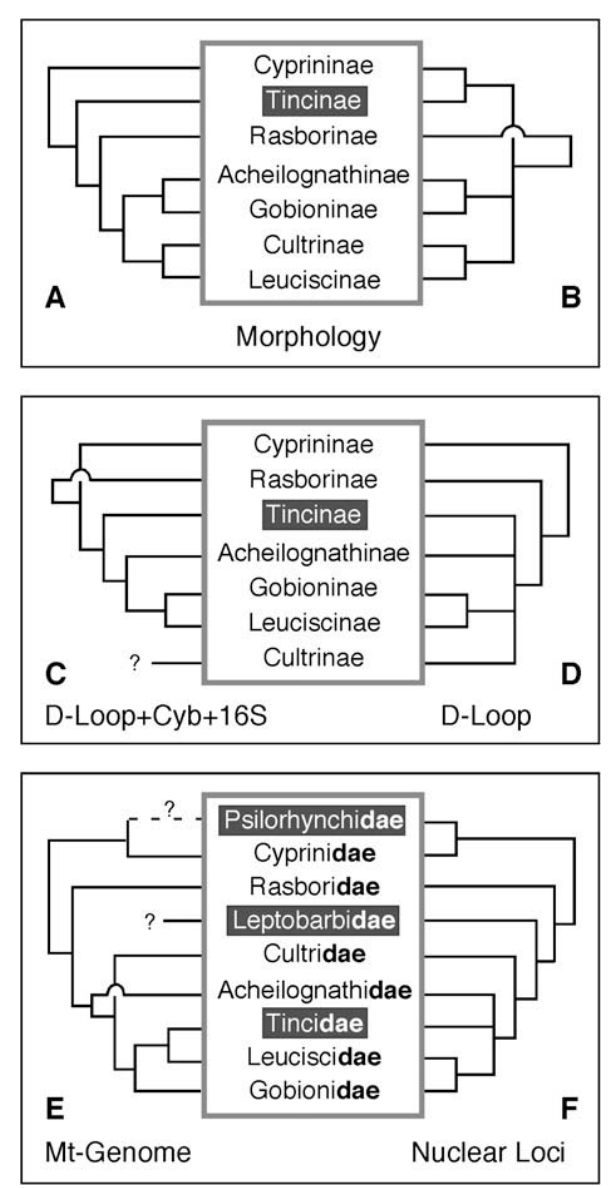

Fig. 1. Previous (A-E) and present $(F)$ hypotheses depicting relationships of major lineages within the Cyprinidae. (A) Cavender and Coburn's (1992) hypothesis based on 47 morphological characters; (B) Most-parsimonious tree found by Cavender and Coburn (1992) based on morphological matrix of Chen et al. (1984); (C) Gilles et al.'s (2001) hypothesis based on 1374 aligned nucleotides from mt-DNA sequences of 16S, D-loop and cytochrome $b$ genes; (D) Liu and Chen's (2003) hypothesis based on 1051 aligned nucleotides from mt-DNA sequences of D-loop; (E) Saitoh et al.'s (2006) hypothesis based on 14,563 aligned nucleotides from whole mt-genomic sequences; (F) Present hypothesis from this study based on 5733 aligned nucleotides from six nuclear genes with suggesting revised phylogenetic classification for the family (see: discussion). The three enigmatic taxa are highlighted. Leuciscinae(-dae) here includes leuciscines and phoxinines. Following results of previous studies of morphology and molecules, Cultrinae(-dae) should include cultrines, xenocyprines plus several other taxa suggested to be included to this group (see: discussion).

of the subfamilies Acheilognathinae, Gobioninae, and Cultrinae than to members of the Rasborinae or Cyprininae (Fig. 1C and D). More recently, using whole mitochondrial genomes, Saitoh et al. (2006) provided a robust phylogenic hypothesis for the main cypriniform lineages for the first time. In their hypothesis, two reciprocal monophyletic groups were resolved: Cobitoidea and Cyprinoidea (or Cyprinidae). Their hypothetical relationships of main cyprind clades were summarized in Fig. 1E. Even if a larger number of characters (e.g. complete mitochondrial genome data) was used, it has limitations to reaching a resolution of certain relationships within the family and some of critical and/or ambiguously classified taxa such as Psilorhynchus and Leptobabrus were missing in the analysis (Fig. 1). Moreover, the resulting hypotheses require further testing with more intensive taxonomic sampling and additional independent molecular markers.

Herein, we employ a multiple nuclear gene (or phylogenomic) approach with a diverse set of 49 cyprinid species to infer evolutionary relationships of the major clades within the Cyprinoidea. We placed particular emphasize on resolving the phylogenetic position of the enigmatic genera Psilorhynchus (the stone carps), Tinca (the tench), and Leptobabrus (the mad barb or sultan fish) in relation to other cyprinid fishes. These enigmatic genera have received little attention from molecular systematists and have been difficult to place within the current cypriniform classification, likely because of morphological divergence. DNA sequence data were generated from six nuclear gene loci (RAG1, Rhodopsin, IRBP, EGR1, EGR2B, and EGR3). These gene markers have recently been shown to be phylogenetically informative in reconstructing the phylogenetic relationships of ray-finned fishes, particularly among fishes of the order Cypriniformes (Chen et al., 2008).

\section{Materials and methods}

\subsection{DNA data collection}

A total of 54 samples were included for investigation. The analytical dataset was composed of DNA sequences of 6 targeted nuclear loci obtained from 2 Psilorhynchus species, Tinca tinca, Leptobarbus hoevenii, 45 other diverse specimens of cyprinids from all recognized subfamily groups, and five outgroups from the superfamily Cobitoidea. Several sequences used in this study have been previously described in Mayden et al. (2008) and Chen et al. (2008). Methods for collecting new DNA data from the specimens and/or gene loci followed the procedures outlined in Chen et al. (2008). The GenBank accession numbers of corresponding gene sequences used in this study are listed in the Table 1.

\subsection{Phylogenetic analysis}

Phylogenetic analyses were based on a partitioned Maximum Likelihood (ML) method and partitioned Bayesian approach (BA) for two different types of character matrices as implemented in the parallel version of RAxML (version 7.0.4) (Stamatakis, 2006) and MrBayes (version 3.1.1) (Huelsenbeck and Ronquist, 2001), respectively. The first matrix was composed of all available characters without employing a particular weighting scheme. As phylogenetic analyses of protein-coding genes can be biased from homoplasy at third codon positions due to multiple substitutions in transitions (Saitoh et al., 2006) and/or because of base composition biases across taxa (Chen et al., 2003; Lockhart et al., 1994), a second matrix (partial RY-coding matrix) was prepared according to the results obtained from absolute saturation tests (Philippe et al., 1994) and from $\chi^{2}$ tests of base composition stationarity performed using PAUP*-version 4.0b10 (Swofford, 2002). As outlined in our previous study, no clear saturation plateau on substitutions in transitions at the third codon position of six nuclear genes used here was detected by comparing the sequences recovering all main lineages of cypriniform species (see Fig. 2 in Chen et al., 2008). However, the tests of base composition stationarity revealed that the Rhodopsin dataset exhibits significant base composition bias across taxa when analyzed using variable sites only and the sites at third codon position for the tests. Thus, we complied an operational dataset in which the nucleotides $\mathrm{A}$ and $\mathrm{G}$ and the nucleotides $\mathrm{T}$ and $\mathrm{C}$ at the third codon position of Rhodopsin were converted into purine $(\mathrm{R})$ and pyrimidine $(\mathrm{Y})$, respectively.

Search for optimal ML trees and Bayesian analyses were performed by a high performance cluster computing facility (with 32 nodes) located at Saint Louis University. We used mixed model analysis, which allows an individual model of nucleotide substitution to be estimated independently from each partition for the analyses. Partitions were assigned with respect to the codon positions of each nuclear protein-coding gene. Likelihood ratio tests (Goldman, 1993), as implemented in MrModeltest 2.2 (Nylander, 2004), were used to choose models for each gene coding position 
Table 1

Cypriniform taxa included in this study and accession numbers of sequences in Genbank.

\begin{tabular}{|c|c|c|c|c|c|c|c|}
\hline \multirow[t]{2}{*}{ Family/subfamily } & \multirow[t]{2}{*}{ Taxon } & \multicolumn{6}{|c|}{ GenBank accession no. } \\
\hline & & RAG1 & $\mathrm{RH}$ & IRBP & EGR1 & EGR2B & EGR3 \\
\hline \multicolumn{8}{|l|}{ Cobitoidea } \\
\hline Balitoridae & Sewellia lineolata & EU409609 & EU409635 & EU409667 & EU409699 & EU409731 & EU409763 \\
\hline Botiidae & Leptobotia pellegrini & EU292683 & EU409640 & EU409672 & EU409704 & EU409736 & EU409768 \\
\hline Cobitidae & Niwaella multifasciata & EU409615 & EU409642 & EU409674 & EU409706 & EU409738 & EU409770 \\
\hline Gyrinocheilidae & Gyrinocheilus aymonieri & EU292682 & FJ197071 & FJ197122 & EU409727 & EU409759 & EU409791 \\
\hline Nemacheilidae & Lefua costata & EU409608 & EU409634 & EU409666 & EU409698 & EU409730 & EU409762 \\
\hline \multicolumn{8}{|l|}{ Cyprinoidea } \\
\hline Psilorhynchidae & Psilorhynchus sucatio & FJ531251 & FJ531355 & FJ531374 & FJ531274 & FJ531303 & FJ531332 \\
\hline Psilorhynchidae & Psilorhynchus homaloptera & FJ531250 & FJ531354 & & FJ531273 & FJ531302 & FJ531331 \\
\hline \multicolumn{8}{|l|}{ Cyprinidae } \\
\hline Acheilognathinae & Acheilognathus tabira & EU409617 & EU409644 & EU409676 & EU409708 & EU409740 & EU409772 \\
\hline Acheilognathinae & Paracheilognathus himantegus & EU409618 & EU409645 & EU409677 & EU409709 & EU409741 & EU409773 \\
\hline Acheilognathinae & Rhodeus ocellatus kurumeus & EU711142 & FJ197043 & FJ197093 & FJ531277 & FJ531306 & FJ531335 \\
\hline Cultrinae & Ischikauia steenackeri & EU292687 & EU409648 & EU409680 & EU409712 & EU409744 & EU409776 \\
\hline Cultrinae & Megalobrama amblycephala & EU409620 & EU409647 & EU409679 & EU409711 & EU409743 & EU409775 \\
\hline Cyprininae & Acrossocheilus paradoxus & FJ531245 & FJ531342 & FJ531362 & FJ531255 & FJ531284 & FJ531313 \\
\hline Cyprininae & Barbonymus gonionotus & FJ531246 & FJ531344 & FJ531364 & FJ531258 & FJ531287 & FJ531316 \\
\hline Cyprininae & Barbus callipterus & FJ531247 & FJ531345 & FJ531365 & FJ531259 & FJ531288 & FJ531317 \\
\hline Cyprininae & Garra spilota & EU409621 & EU409649 & EU409681 & EU409713 & EU409745 & EU409777 \\
\hline Cyprininae & Gymnocypris przewalskii & EU711149 & FJ197051 & FJ197102 & FJ531265 & FJ531294 & FJ531323 \\
\hline Cyprininae & Hampala macrolepidota & EU409623 & EU409651 & EU409683 & EU409715 & EU409747 & EU409779 \\
\hline Cyprininae & Labeo chrysophekadion & EU409622 & EU409650 & EU409682 & EU409714 & EU409746 & EU409778 \\
\hline Cyprininae & Puntius titteya & EU292685 & FJ531356 & FJ531375 & FJ531275 & FJ531304 & FJ531333 \\
\hline Gobioninae & Biwia zezera & EU409626 & EU409654 & EU409686 & EU409718 & EU409750 & EU409782 \\
\hline Gobioninae & Gobio gobio & EU292689 & FJ197056 & FJ197107 & FJ531264 & FJ531293 & FJ531322 \\
\hline Gobioninae & Hemibarbus barbus & EU711154 & FJ197057 & FJ197108 & FJ531266 & FJ531295 & FJ531324 \\
\hline Gobioninae & Romanogobio ciscaucasicus & EU409624 & EU409652 & EU409684 & EU409716 & EU409748 & EU409780 \\
\hline Gobioninae & Sarcocheilichthys parvus & EU409625 & EU409653 & EU409685 & EU409717 & EU409749 & EU409781 \\
\hline Gobioninae & Squalidus chankaensis & FJ531252 & FJ531358 & FJ531377 & FJ531278 & FJ531307 & FJ531336 \\
\hline Leuciscinae & Notropis baileyi & EU292691 & EU409657 & EU409689 & EU409721 & EU409753 & EU409785 \\
\hline Leuciscinae & Pelecus cultratus & EU711144 & FJ197045 & FJ197095 & FJ531272 & FJ531301 & FJ531330 \\
\hline Leuciscinae & Phoxinus perenurus sachalinensis & EU409627 & EU409655 & EU409687 & EU409719 & EU409751 & EU409783 \\
\hline Leuciscinae & Scardinius erythrophthalmus & EU409628 & EU409656 & EU409688 & EU409720 & EU409752 & EU409784 \\
\hline Leuciscinae & Semotilus atromaculatus & EU409629 & EU409658 & EU409690 & EU409722 & EU409754 & EU409786 \\
\hline Rasborinae & Aphyocypris chinensis & EU292692 & FJ197066 & FJ197117 & FJ531256 & FJ531285 & FJ531314 \\
\hline Rasborinae & Aspidoparia morar & EU711105 & FJ531343 & FJ531363 & FJ531257 & FJ531286 & FJ531315 \\
\hline Rasborinae & Barilius bendelisis & EU292693 & FJ531346 & FJ531366 & FJ531260 & FJ531289 & FJ531318 \\
\hline Rasborinae & Danio albolineatus & EU292696 & EU409661 & EU409693 & EU409725 & EU409757 & EU409789 \\
\hline Rasborinae & Danio dangila & EU292697 & EU409660 & EU409692 & EU409724 & EU409756 & EU409788 \\
\hline Rasborinae & Danio rerio & U71093 & L11014 & X85957 & NM 131248 & NM_130997 & scaffold2320.1 \\
\hline Rasborinae & Danionella mirifica & EU292700 & FJ531347 & FJ531367 & FJ531261 & FJ531290 & FJ531319 \\
\hline Rasborinae & Devario regina & EU292701 & FJ531348 & FJ531368 & FJ531262 & FJ531291 & FJ531320 \\
\hline Rasborinae & Esomus longimanus & FJ531248 & FJ531349 & FJ531369 & FJ531263 & FJ531292 & FJ531321 \\
\hline Rasborinae & Horadandia atukorali & EU292703 & FJ531350 & FJ531370 & FJ531267 & FJ531296 & FJ531325 \\
\hline Rasborinae & Luciosoma setigerum & EU292704 & FJ531352 & FJ531372 & FJ531269 & FJ531298 & FJ531327 \\
\hline Rasborinae & Macrochirichthys macrochirus & EU409630 & EU409659 & EU409691 & EU409723 & EU409755 & EU409787 \\
\hline Rasborinae & Microrasbora kubotai & EU292707 & FJ531353 & FJ531373 & FJ531270 & FJ531299 & FJ531328 \\
\hline Rasborinae & Opsariichthys uncirostris & FJ197126 & FJ197068 & FJ197119 & FJ531271 & FJ531300 & FJ531329 \\
\hline Rasborinae & Rasbora bankanensis & EU292709 & FJ531357 & FJ531376 & FJ531276 & FJ531305 & FJ531334 \\
\hline Rasborinae & Rasbora steineri & EU409631 & EU409662 & EU409694 & EU409726 & EU409758 & EU409790 \\
\hline Rasborinae & Tanichthys albonubes & FJ531253 & FJ531359 & FJ531378 & FJ531279 & FJ531308 & FJ531337 \\
\hline Rasborinae & Trigonostigma heteromorpha & EU292712 & FJ531360 & FJ531379 & FJ531281 & FJ531310 & FJ531339 \\
\hline Rasborinae & Zacco sieboldii & EU292713 & FJ197069 & FJ197120 & FJ531283 & FJ531312 & FJ531341 \\
\hline Tincinae & Tinca tinca & EU711162 & FJ197070 & FJ197121 & FJ531280 & FJ531309 & FJ531338 \\
\hline Unknown & Leptobarbus hoevenii & FJ531249 & FJ531351 & FJ531371 & FJ531268 & FJ531297 & FJ531326 \\
\hline Unknown & Paralaubuca typus & EU409619 & EU409646 & EU409678 & EU409710 & EU409742 & EU409774 \\
\hline Unknown & Yaoshanicus arcus & FJ531254 & FJ531361 & FJ531380 & FJ531282 & FJ531311 & FJ531340 \\
\hline
\end{tabular}

in Partitioned BA. The parameters for running MrBayes were set as follows: "Iset nst $=6$ " (GTR), "lset nst $=2$ " $(\mathrm{HKY})$, "lset nst $=1$ " (F81), "rates = invgamma" (G+I), or "rates = gamma" (G), "unlink" (unlinking of model parameters across data partitions), and "prset ratepr = variable" (rate multiplier variable across data partitions). Two independent Bayesian searches were conducted for each dataset. Four independent MCMC chains were performed with $3,000,000$ replicates, sampling one tree per 100 replicates for each run. The distribution of log likelihood scores was examined to determine stationarity for each search and to decide if extra runs were required to achieve convergence in log likelihoods among runs or searches. We discarded initial trees with non-stationary log likelihood values as part of a burn-in procedure, and combined the remaining trees that resulted in convergent log likelihood scores from both independent searches. These trees were used to construct a $50 \%$ majority rule consensus tree. For ML search with the mixed model of nucleotide substitution we used a GTR $+\mathrm{G}+\mathrm{I}$ model (with four discrete rate categories) for each partition because RAxML only provides GTR related models (GTR $+\mathrm{G}$, GTR + G + I and GTR + CAT approximation) of rate heterogeneity for nucleotide data (Stamatakis, 2006). ML tree search was conducted by performing 100 distinct runs using the default algorithm of the program from complete random trees (-d option) as a starting tree for each run. The final tree was determined by a compar- 


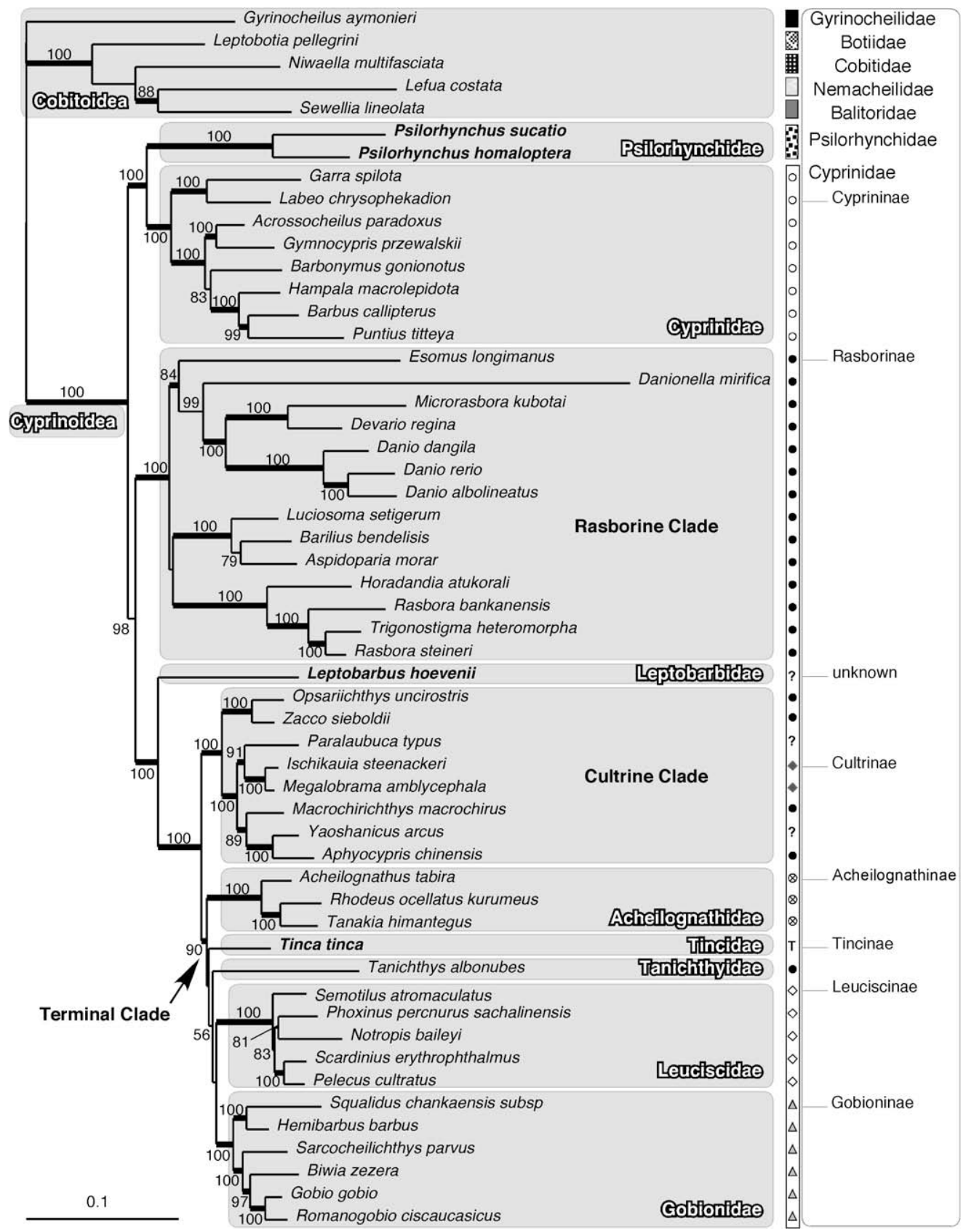

Fig. 2. Phylogenetic tree depicting relationships of the major clades resolved within the family Cyprinidae (or the superfamily Cyprinoidea). Relationships were obtained using partitioned ML analysis of 5733 aligned nucleotides from six nuclear gene loci. ML score of the tree is -53906.500279 . Branch lengths are proportional to inferred character substitutions under GTR + G + I model. Numbers on branches are ML bootstrap values; those below 50\% are not shown. Bold branches on topologies indicate statistically robust nodes with a posteriori probabilities from partitioned Bayesian analysis $\geqslant 0.95$ and resulting MP bootstraps $>$ than $80 \%$. The targeted taxa in this study, Psilorhynchus, Tinca and Leptobarbus are marked in bold. The bars and symbols on the right indicate traditional classification of taxa in Cypriniformes at family/subfamily level. A suggesting revised classification, based on robust molecular evidence from this study, is revealed by gray shadow rectangles on the topology.

ison of likelihood scores under GTR + G + I model among suboptimal trees obtained per run.

Nodal support was assessed using the bootstrap (BS) procedure (Felsenstein, 1985) under Maximum Parsimony (MP) and Maximum Likelihood (ML) criterion, based on 1000 pseudo-replicates and the resulting a posteriori probabilities from partitioned BA. The studies on experimental simulation suggest that, being more conservative, the nonparametric bootstrap approach might be less prone to strongly supporting a false phylogenetic hypothesis, while posterior probabilities put overconfidence on a given phylogenetic hypothesis (Douady et al., 2003). In the present study, we set up posterior probabilities and nonparametric bootstrap support (especially from MPBS) as potential upper and lower bounds of node robustness for our inferred phylogenetic trees (bold branches in Fig. 2). For the MPBS analyses using PAUP*, optimal trees were obtained by heuristic searches with random stepwise addition sequences followed by TBR swapping for 100 replications (Swofford, 2002). The MLBS results (through analyses using RAxML webservers) (Stamatakis et al., 2008) were obtained from the CIPRES cluster (CIPRES Portal v 1.13) at the San Diego Supercomputer Center at http://www.phylo.org/sub_sections/portal/. 


\section{Results and discussion}

\subsection{Characteristics of sequence data and inferred phylogenetic tree}

A total of $5733 \mathrm{bp}$ were aligned for the exon regions of six nuclear genes for 54 taxa (including five outgroups) sampled in this study. The length of aligned sequences from each locus was $1497 \mathrm{bp}$ (RAG1), 819 bp (RH), 849 bp (IRBP), 846 bp (EGR1), 816 (EGR2B), and 906 (EGR3). No internal indels were found among aligned sequences for RAG1, RH, IRBP, and EGR2B datasets. A few indels needed to be introduced in adjusting sequences alignment of EGR1 and 3 genes, but the alignment can be unambiguously achieved followed by triplet codes for amino acids. Of 5733 nucleotides, 2497 were variable sites in which 1996 were parsimony informative. The second or partial RYcoding matrix presented 2407 variable sites in which 1901 were parsimony informative. Relationships of taxa derived from partitioned ML and Bayesian analyses of DNA sequences based on matrix 1 and 2 were nearly identical with slightly differences in relationships where nodal supports are weak; only the ML tree derived from the second (partial RY-coding) matrix is presented herein (Fig. 2). As shown, most of resulting clades were highly supported by partitioned MLBS, MPBS and a posteriori probabilities from partitioned BA(Fig. 2). Accordingly, 10 fully resolved clades or major lineages (as represented by gray shadow rectangles on the topology of Fig. 2) have emerged from the analyses in the present dataset.

\subsection{Phylogenetic relationships of the major clades of cyprinid fishes}

In all resulting phylogenies (all analyses), Cyprinidae is revealed as paraphyletic group with respect to the Psilorhynchidae. Within the Cyprinidae except for Rasborinae, the currently recognized cyprinid subfamilies were found to represent monophyletic groupings with strong nodal supports. As shown in ML tree with partial RY-coding analysis (Fig. 2), the Cyprininae and Psilorhynchidae are sister-groups to each other. These two clades together form the basal sister-group to the other cyprinid taxa shown in the tree.

Species currently placed within the Rasborinae appear to have five distinct origins among cyprinids. Among 19 rasborine species sampled in this study, 14 species group together in a robust clade or Rasborinae-2 clade sensu Conway et al. (2008). This rasborine clade can be subdivided into three strongly supported subgroups. The first subgroup includes species of Luciosoma, Barilius and Aspidoparia, which forms the sister-group to the subgroup containing species of Rasbora, Trigonostiga and Horadandia in the partial RYcoding ML analysis (Fig. 2). The remaining subgroup, which includes species of Esomus, Danionella, Microrasbora, Devario and Danio, forms the sister-group to a clade composed of two other subgroupings. In equal-weighting ML and BA analyses and partial RY-coding BA analysis, the first subgroup is resolved as the most basal lineage within the rasborine clade (not shown). This result corroborates to the findings from a recent study investigating inter-relationships among 31 rasborine taxa with RAG1 sequence data (Conway et al., 2008) but none of the studies with involved analyses resolve confidently the inter-relationships among these three mentioned rasborine subgroups in terms of statistical nodal supports. Otherwise, most of intra-relationships within the subgroups are well resolved in this study (Fig. 2).

Four of five remaining "rasborine" taxa sampled in this study (Opsariichthys, Zacco, Macrochirichthys, and Aphyocypris) appear in three different placements in the tree and are more closely related to members of the Cultrinae and 2 other cyprinids with uncertain classification (Yasoshanicus and Paralaubuca). We refer to this wellsupported monoplyletic group as the "cultrine" clade. These results, indicating a closer evolutionary affinity among certain rasborine species and cultrine species, are consistent with the findings of other previous phylogenetic analyses based on either mitochon- drial or nuclear DNA sequence data (e.g. Saitoh etal., 2006; Conway et al., 2008; He et al., 2008b; Mayden et al., 2008).

The last rasborine species sampled in this study, Tanichthys albonubes, is nested within the terminal clade of the tree and separate from all other rasborines. Members from this clade represent many species endemic to Eurasia and North America from the cyprinid subfamilies Acheilognathinae, Gobioninae, Tincinae, and Leuciscinae (Fig. 2). Within the terminal clade, several subgroups were supported as monophyletic, notably at subfamily level. In all analyses, a sister-group relationship between the Leuciscinae and Gobioninae was recovered, but received only weak nodal support. This relationship is supported by previous molecular studies (Gilles et al., 2001; Liu and Chen, 2003) (Fig. 1), and in most of the resulting phylogenies based on varied analytical methods and datasets (four nuclear loci and whole mt-genomic data) in a recent study (Mayden et al., 2009).

Finally, another taxon of our interest, Leptobarbus, forms the sister-group to the clutrine clade plus the terminal clade of cyprinids described above. This relationship is strongly supported (100\% for MLBP, BPBP, and a posteriori probabilities) (Fig. 2).

Overall, most of the phylogenetic relationships among cyprinid fishes presented here are well resolved using the DNA data from six nuclear loci (5733 bp). The results presented are largely congruent with the resulting cypriniform phylogeny using wholemitogenome data (14,563 bp) (Saitoh et al., 2006). All of these steady molecular evidences currently established are challenging the morphological hypotheses and the classification of this group requires a further revision (see below: Section 3.4).

\subsection{Systematics of Tinca, Psilorhynchus, and Leptobarbus}

The systematic status of the genus Tinca, and Psilorhynchus is historically chaotic. As Howes (1991) stated, the inclusion of monotypic genus Tinca in any of the cyprind subgroups is a taxonomic problem. For instance, two of the available morphological studies attempting to resolve the phylogenetic placement of Tinca among other cyprinids disagreed with each other (Cavender and Coburn, 1992; Chen et al., 1984) (Fig. 1A and B). Accordingly, erection of the subfamily Tincinae for Tinca became an optimal solution, yet its relationships remain uncertain. Early molecular hypotheses derived from mitochondrial sequence data rejected the morphological hypotheses and showed a closer evolutionary affinity of Tinca with acheilognathines, gobionines, leuciscines, and cultrines (Fig. 1C and D). Recent mt-genomic analysis identifies the phylogenetic position of the Tincinae, which should appear to be the sister-taxa to the Leuciscinae (Fig. 1E). Our resulting phylogeny, cannot further confirm this particular molecular hypothesis, as the corresponding nodes for those concerned relationships are weakly supported (Fig. 2). Nonetheless the hypothesis (as shown in Saitoh et al., 2006; Liu and Chen, 2003) (Fig. 1D and E) implicating that cultrine taxa have closely affinity to the Tincinae and to the remaining cyprinids (excluding cyprinines and "rasborines") is less likely. Indeed, we resolve that Tinca is a member of the terminal clade of cyprinids (Fig. 1F; Fig. 2), the monophyly of which is highly supported.

Regarding the placement of the genus Psilorhynchus within the Cypriniformes, over the last two centuries this genus has been placed with different loach families (either Balitoridae or Cobitidae) or within the Cyprinidae (see Conway and Mayden, 2007; Šlechtová et al., 2007). The only morphological hypothesis applying phylogenetic analysis with relevant taxa from all families of the Cypriniformes showed that Psilorhynchus is the sister-taxa to a clade including cobitids and balitorids (Conway and Mayden 2007). Saitoh et al. (2006) did not include this taxa in their analysis. An alternative study using whole mt-genomic data with 17 representatives from the order Cypriniformes He et al. (2008a) identified Psilorhynchus and the Cyprininae as sister-group to each other. Our present study confirms this hypothesis. 
Finally, prior to our study, no systematic study, inclusive of the genus Leptobarbus, had been conducted. Leptobarbus was included as member of the "Danioninae (possibly following Gosline, 1975) in the generic distribution list of cyprinids occurring in South East Asia by Rainboth (1991). In this study, we discover the systematic status of the genus Leptobarbus to be of intermediate position in the cyprind tree (Fig. 2). Four descried species are presented in the genus. Those are species native to South Asia from Thailand to Sumatra and Borneo. They may reach up to about $60 \mathrm{~cm}$ long. Interestingly, this huge taxon is the sister-group of an extremely diverse group comprising a large number of cyprinid species with highly diverse body shapes and sizes, occurring in different ecosystems.

\subsection{Concluding remarks with taxonomy implication}

According to the solid molecular evidence presented here, which supports the existence of ten monophyletic groups of cyprinid (or cyprinoid) fishes, we tentatively suggest the following revisions to the current cypriniform classification. Five of the subfamilies of the Cyprinidae (Cyprinae, Acheilognathinae, Tincinae, Leuciscinae, and Gobioninae) (Howes, 1991; Nelson, 2006) that have been previously recognized and widely believed to represent monophyletic groupings should be elevated from subfamily status to family status under the superfamily Cyprinioidea. The family group name Psilorhynchidae, which has been previously accepted by numerous authors (Conway and Mayden, 2007; Nelson, 2006; Ramaswami, 1952) should be retained. Erection of new cyprinoid families (Leptobarbidae and Tanichthyidae) for two distinct lineages revealed from our analyses containing the species from Leptobarbus and Tanichthys, respectively is recommended. We would also need to give the relevant family names for the clades discovered in this study. There are two clades (rasborine and cultrine clades) containing, respectively, major rasborine species and cultrine species plus their putative allies such as Opsariichthys, Zacco, Paralaubuca, Macrochirichthys, Yaoshanicus, Aphyocypris, taxa from "Xenocyprinae", and taxa from "Squaliobarbinae" that are identified in this study (Fig. 2) and in some other molecular studies (He et al., 2008b; Liu and Chen, 2003; Mayden et al., 2008; Saitoh et al., 2006). Finally, ten families herein are suggested to be recognized for the Cyprinoidea with respect to seven families for its reciprocal superfamily Cobitoidea (Šlechtová et al., 2007).

\section{Acknowledgments}

We greatly thank Kevin L. Conway for providing valuable comments for this work and for manuscript-improvement. We thank Maski Miya, Tetsuya Sado, and Shunping He for the specimens. This research is part of an ongoing international Tree of Life initiative on the order Cypriniformes USA NSF awards EF 0431326.

\section{References}

Cavender, T.M., Coburn, M., 1992. Phylogenetic relationships of North American Cyprinidae. In: Mayden, R.L. (Ed.), Systematics, Historical Ecology and North American Freshwater Fishes. Standford University Press, Stanford, pp. 328-378.

Chen, W.-J., Bonillo, C., Lecointre, G., 2003. Repeatability of clades as criterion of reliability: a case study for molecular phylogeny of Acanthomorpha (Teleostei) with larger number of taxa. Mol. Phylogenet. Evol. 26, 262-288.

Chen, W.-J., Miya, M., Saitoh, K., Mayden, R.L., 2008. Phylogenetic utility of two existing and four novel nuclear gene loci in reconstructing Tree of Life of ray-finned fishes: the order Cypriniformes (Ostariophysi) as a case study. Gene 423, 125-134.

Chen, X., Yue, P., Lin, R., 1984. Major groups within the family Cyprinidae and their phylogenetic relationships. Act. Zoo. Sinica 9, 424-440.

Chen, Y., 1981. Investigation of the systematic position of Psilorhynchus (Cyprinoidei, Pisces). Acta Hydrobio. Sinica 7, 371-376.

Conway, K.W., Mayden, R.L., 2007. The gill-arches of Psilorhynchus (Ostariophysi: Psilorhynchidae). Copeia 2007, 267-280.

Conway, K.W., Chen, W.-J., Mayden, R.L., 2008. The celestial pearl danio is a miniature Danio (s.s) (Ostariophysi: Cyprinidae): evidence from morphology and molecules. Zootaxa 1686, 1-28.
Cunha, C., Mesquita, N., Dowling, T.E., Gilles, A., Coelho, M.M., 2002. Phylogenetic relationships of Eurasian and American cyprinids using cytochrome $b$ sequences. J. Fish Biol. 61, 929-944.

Douady, C.J., Delsuc, F., Boucher, Y., Doolittle, W.F., Douzery, E.J., 2003. Comparison of Bayesian and maximum likelihood bootstrap measures of phylogenetic reliability. Mol. Biol. Evol. 20, 248-254.

Felsenstein, J., 1985. Confidence limits on phylogenies: an approach using the bootstrap. Evolution 39, 783-791.

Gilles, A., Lecointre, G., Miquelis, A., Loerstcher, M., Chappaz, R., Brun, G., 2001. Partial combination applied to phylogeny of European cyprinids using the mitochondrial control region. Mol. Phylogenet. Evol. 19, 22-33.

Goldman, N., 1993. Statistical tests of models of DNA substitution. J. Mol. Evol. 36, $182-198$.

Gosline, W.A., 1975. The cyprinid dermosphenotic and the subfamily Rasborinae. Occ. Pap. Mus. Zool., Univ. Mich 673, 1-13.

He, S., Gu, X., Mayden, R.L., Chen, W.-J., Conway, K.W., Chen, Y., 2008a. Phylogenetic position of the enigmatic genus Psilorhynchus (Ostariophysi: Cypriniformes): evidence from the mitochondrial genome. Mol. Phylogenet. Evol. 47, 419-425.

He, S., Mayden, R.L., Wang, X., Wang, W., Tang, K.L., Chen, W.-J., Chen, Y., 2008b. Molecular phylogenetics of the family Cyprinidae (Actinopterygii: Cypriniformes) as evidenced by sequence variation in the first intron of S7 ribosomal protein-coding gene: further evidence from a nuclear gene of the systematic chaos in the family. Mol. Phylogenet. Evol. 46, 818-829.

Hora, S.L., 1925. Notes of fishes in the Indian Museum. 12. The sysytematic position of the cyprinoid genus Psilorhynchus McClelland. Rec. Indian Mus. 27, 457-460.

Howes, G.J., 1991. Systematics and biogeography: an overview. In: Winfield, I.J., Nelson, J.S. (Eds.), Cyprinid Fishes Systematics, Biology and Exploitation. Chapman and Hall, London, pp. 1-33.

Huelsenbeck, J.P., Ronquist, F., 2001. MRBAYES. Bayesian inference of phylogeny. Bioinformatics 17, 754-755.

Liu, H., Chen, Y., 2003. Phylogeny of the East Asian cyprinids inferred from sequences of mitochondrial DNA control region. Can. J. Zool. 81, 1938-1946.

Lockhart, P.J., Steel, M.A., Hendy, M.D., Penny, D., 1994. Recovering evolutionary trees under a more realistic model of sequence evolution. Mol. Biol. Evol. 11, 605-612.

Mayden, R.L., Chen, W.-J., Bart, H.L., Doosey, M.H., Simons, A.M., Tang, K.L., Wood, R.M., Agnew, M.K., Yang, L., Hirt, M.V., Clements, M.D., Saitoh, K., Sado, T., Miya, M., Nishida, M., 2009. Reconstructing the phylogenetic relationships of the Earth's most diverse clade of freshwater fishes - order Cypriniformes (Actinopterygii: Ostariophysi): a case study using multiple nuclear loci and the mitochondrial genome. Mol. Phylogenet. Evol. 51, 500-514.

Mayden, R.L., Tang, K.L., Wood, R.M., Chen, W.-J., Agnew, M.K., Conway, K.W., Yang, L., Simons, A.M., Bart, H.L., Harris, P.M., Li, J., Wang, X., Saitoh, K., He, S., Liu, H., Chen, Y., Nishida, M., Miya, M., 2008. Inferring the Tree of Life of the order Cypriniformes, the earth's most diverse clade of freshwater fishes: implications of varied taxon and character sampling. J. Syst. Evol. 46, 424-438.

Nelson, J.S., 1994. Fishes of the World, third ed. John Wiley \& Sons, Inc., New York. Nelson, J.S., 2006. Fishes of the World, fourth ed. John Wiley \& Sons, Inc., Hoboken, NJ.

Nylander, J.A.A., 2004. MrModeltest v2. Program distributed by the author. Evolutionary Biology Centre, Uppsala University.

Okazaki, M., Naruse, K., Shima, A., Arai, R., 2001. Phylogenetic relationships of bitterings based on mitochondrial $12 \mathrm{~S}$ ribosomal DNA sequences. J. Fish Biol. 58, 89-106.

Philippe, H., Sorhannus, U., Baroin, A., Perasso, R., Gasse, F., Adoutte, A., 1994. Comparison of molecular and paleontological data in diatoms suggests a major gap in the fossil record. Mol. Phylogenet. Evol. 7, 247-265.

Rainboth, W.J., 1991. Cyprinids of South East Asia. In: Winfield, I.J., Nelson, J.S. (Eds.), Cyprinid Fishes Systematics, Biology and Exploitation. Chapman and Hall, London, pp. 156-210.

Ramaswami, L.S., 1952. Skeleton of cyprinoid fishes in relation to phylogenetic studies. II. The systematic position of Psilorhynchus McClelland. Proc. Nat. Inst. Sci. India 18, 141-150.

Saitoh, K., Sado, T., Mayden, R.L., Hanzawa, N., Nakamura, K., Nishida, M., Miya, M., 2006. Mitogenomic evolution and interrelationships of the Cypriniformes (Actinopterygii: Ostariophysi): the first evidence toward resolution of higherlevel relationships of the world's largest freshwater fish clade based on 59 whole mitogenome sequences. J. Mol. Evol. 63, 826-841.

Simons, A.M., Berentzen, P., Mayden, R.L., 2003. Molecular systematics of North American phoxinin genera (Actinopterygii: Cyprinidae) inferred from mitochondrial 12S and 16S ribosomal RNA sequences. Zool. J. Linn. Soc. 139, 63-80.

Šlechtová, V., Bohlen, J., Tan, H.H., 2007. Families of Cobitoidea (Teleostei; Cypriniformes) as revealed from nuclear genetic data and the position of the mysterious genera Barbucca, Psilorhynchus, Serpenticobitis and Vaillantella. Mol. Phylogenet. Evol. 44, 1358-1365.

Stamatakis, A., 2006. RAxML-VI-HPC: maximum likelihood-based phylogenetic analyses with thousands of taxa and mixed models. Bioinformatics 22, 2688-2690.

Stamatakis, A., Hoover, P., Rougemont, J., 2008. A rapid bootstrap algorithm for the RAxML web-servers. Syst. Biol. 57, 758-771.

Swofford, D.L., 2002. PAUP*. Phylogenetic Analysis Using Parsimony (*and Other Methods). Version 4. Sinauer Associates, Sunderland, Massachusetts.

Xiao, W., Zhang, Y., Liu, H., 2001. Molecular systematics of Xenocyprinae (teleostei: cyprinidae): taxonomy, biogeography, and coevolution of a special group restricted in East Asia. Mol. Phylogenet. Evol. 18, 163-173.

Zardoya, R., Doadrio, I., 1998. Phylogenetic relationships of Iberian cyprinids: systematic and biogeographical implications. Proc. Biol. Sci. 265, 1365-1372. 